\title{
DELINEATION OF SUITABLE CROPLAND AREAS USING A GIS BASED MULTI- CRITERIA EVALUATION APPROACH IN THE CENTRAL AGRICULTURAL REGION OF MONGOLIA
}

\author{
Altantuya Dorjsuren ${ }^{1,3}$, Bayartungalag Batsaikhan ${ }^{1,3 *}$, Badamgarav Gansukh ${ }^{2,3}$, Chuluunbaatar Jamsran ${ }^{2}$, Elbegjargal Nasanbat ${ }^{3}$, \\ Odgerel Bold ${ }^{3}$, \\ ${ }^{1}$ Institute of Geography and Geoecology, Mongolian Academy of Sciences, Ulaanbaatar-15170, Mongolia - \\ bayartungalag_b@mas.ac.mn \\ ${ }^{2}$ Mongolian University of Life Sciences, Zaisan-17024, Ulaanbaatar, Mongolia \\ ${ }^{3}$ Mongolian Geo-spatial Association, Ulaanbaatar-15141, Mongolia
}

KEY WORDS: Suitable area for cropland, Central agriculture region, Mongolia

\begin{abstract}
:
The central agricultural region, a typically main agricultural zone of Mongolia. The area has undergone rapid agricultural land-use changes including land reclamation and cropland abandonment in the last decades due to growing population and food demand, climatic variability, and land-use policy. The utilization of the land is often unmatched with the inherent suitability of the land. Identification of the spatial distribution of suitable areas for cropland is essential for sustainable land-use recommendation. The objective of this study to delineate the areas suitable for cropland in the central agricultural region using a GIS-based multi-criteria evaluation of biophysical factors and multi-sensor data. We used 47 metrological station data of 10 years including temperature, precipitation, and solar radiation with topographic, soil property, landscape, and natural region map. The results indicate a suitable location and extent of crop farming areas at different suitability levels. The results can be used to identify priority areas for crop farming and sustainable land-use management.
\end{abstract}

\section{INTRODUCTION}

The central region of Mongolia, a typical agro-pastoral transitional zone, has undergone rapid agricultural land-use changes including land reclamation and cropland abandonment in past decades due to growing population and food demand, climatic variability, and land-use policy. The utilization of the land is often unmatched with the inherent suitability of the land. Identification of the spatial distribution of suitable areas for cropland is essential for sustainable land-use recommendation. It is significant to the regional ecology and sustainability to examine the pattern and its rationality of land-use change (Jinwei Dong 2011).

Crop-land suitability analysis is a prerequisite to achieve optimum utilization of the available land resources for sustainable agricultural production. One of the most important and urgent problems in Mongolia is to improve agricultural land management and cropping patterns to increase the agricultural production with efficient use of land resources. In Mongolia, agriculture is the mainstay of the national economy. The main vegetable imports (onion, garlic, cabbage, turnips, and other root seed vegetables) increased from 5438.4 tons in 1995 to 64,107 tons in 2016, an increase of 11.7 times. Of these, $96 \%$ 99\% were imported from China (Munkhdulam Otgonbayar et al., 2017). Mongolia remains strongly dependent on food security from neighboring countries. In addition, soils of currently cultivated areas are degrading. The country is facing challenges (especially local governments and community groups) to identify new crop areas with enough capacity for cultivation (Munkhdulam Otgonbayar et al., 2017).

In other studies, previously studied this topic: "Land suitability evaluation for cropland based on GIS between 2014 and 2016", was funded by the Mongolian Agency of Administration of Land Affairs, Geodesy and Cartography. In our preliminary study we used small and medium scale digital thematic maps to analyze and assess land suitability for cropland. During the study it was recognized that there was a need to improve the accuracy of input data using high-resolution satellite imagery for future research (Munkhdulam et al., 2016). In addition, maximum likelihood supervised classification was applied to Landsat TM and ETM images acquired in 1989 and 2000, respectively, to map cropland area cover changes in the Selenge province of Mongolia. A supervised classification was carried out on the six reflective bands (bands 1-5 and band 7) for the two images individually with ground-based agricultural monitoring data (Erdenee and Ryutaro Tateishi, 2010). The central region of Mongolia the 450,000 hectares of cultivated land used for agricultural purposes has not been used (Jaehne,G., 1990). Therefore, we have a rationale for conducting this study. The objective of this study to delineate the areas suitable for cropland in the central agricultural region using a GIS-based multi-criteria evaluation of biophysical factors and multi-sensor data. We used 47 metrological station data of 10 years including temperature, precipitation, and solar radiation with topographic, soil property, landscape, and natural region map. The results indicate a suitable location and extent of crop farming areas at different suitability levels. The results can be used to identify priority areas for crop farming and sustainable land-use management.

\section{MATERIALS AND METHODS}

\subsection{Study area}

Mongolia is situated between Central Asian high mountain ranges at the altitude of $1580 \mathrm{~m}$ above sea level, and displays harsh continental climatic conditions. The central Agriculture region has a high population density and a large number of

\footnotetext{
* Corresponding author
} 
mining- extractive industries; thus, the region plays a crucial role in the socio-economic development of Mongolia. The central Agriculture region includes seven provinces; Arkhangai, Bulgan, Ovorkhangai, Selenge, Tov, Khentii, Darkhan-Uul, where the core development centers are Orkhon, Ulaanbaatar city. Mongolia is divided into five different agro-ecological regions, which reflect distinct geographical patterns of agricultural production and climate (Battsetseg Tuvdendorj, Bingfang Wu et al., 2019). The geographic boundaries of the area are $47^{\circ} 47^{\prime} 51.6^{\prime \prime} \mathrm{N}-47^{\circ} 49^{\prime} 25.3^{\prime \prime N}$ and $98^{\circ} 11^{\prime} 35.2^{\prime \prime} \mathrm{E}$ $112^{\circ} 44^{\prime} 21.9^{\prime \prime} \mathrm{E}$ (Fig. 1). It is situated between approximately 589 and $3587 \mathrm{~m}$ above sea level and there are forty-seven climate stations in seven provinces (Fig. 1). The main characteristics of extreme climate in Mongolia include long-lasting cold winters, occasionally unexpectedly cold summers, hot days and cold nights, high-speed daytime winds and lower-speed nighttime winds, and a lack of rainfall. The average long-term air temperature is from -2.1 to $+4.0^{\circ} \mathrm{C}$ in this region. In the Central region, annual precipitation varies between $50-450 \mathrm{~mm}$, depending on elevation, natural zones, and belts. The soil latitude zone is clearly visible, its origins due to the presence of steppe forests, steppes, desert steppes, and desert zones (Ecosystems of Mongolia Atlas., 2019).

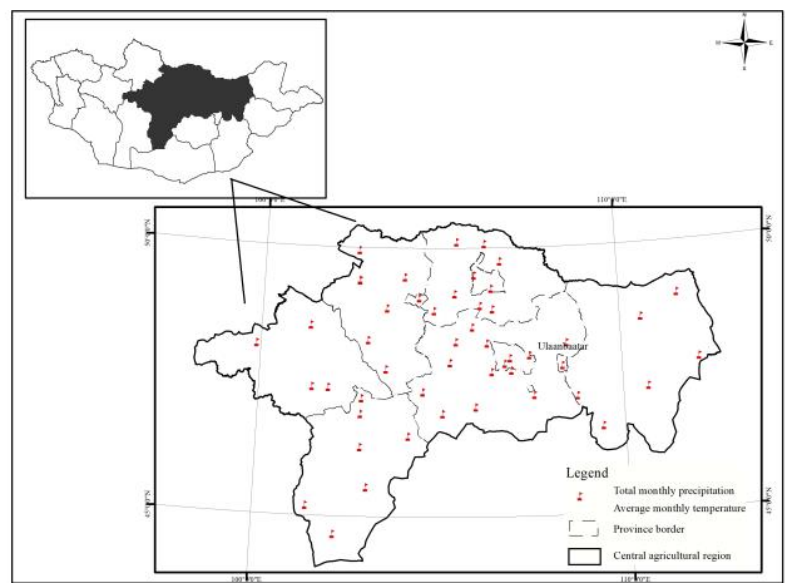

Figure 1. Location map of the study area.

\subsection{Data used in the land suitability analysis}

The suitability analysis data that were used in this study were acquired from three sources. Based on the criteria of climate, soil, and topographic, selecting central-growing areas requires the consideration of many factors, including precipitation, temperature, solar radiation, soil type, Soil humus, elevation, slope, aspect, and vegetation cover. Precipitation and air temperature are important meteorological parameters that significantly impact agricultural productivity. Climate station data which are: temperature, precipitation obtained from fortyseven climate stations from April - September, 2009-2019 for vegetation growing season. Precipitation $(\mathrm{mm})$ and temperature $\left({ }^{\circ} \mathrm{C}\right)$ data acquired monthly mean which is based on daily observation data. Total solar radiation obtained from fourteen climate stations from April - September, for vegetation growing season.

These climate data were provided by the Information and Research Institute of Meteorology, Hydrology and Environment (IRIMHE) of Mongolia. The station locations are distributed within the study area in Fig. 1. The average temperature in Mongolia in July 2009-2019 is between 14-22 degrees. It is slightly cold in the back of the Khentii mountain range and warm in the rest of the Khangai mountain range. Total solar radiation is solar brightness is good throughout the whole area, it is 4-9 $\mathrm{ml}$ joules on average (Fig. 2).

A digital elevation model (DEM) of the study area, for the year 2011, was downloaded from USGS as https://earthexplorer.usgs.gov/. The DEM dataset was derived from a topographic map with a resolution of $30 \mathrm{~m}$. The data of raster parameters such as the slope and aspect resulted from the DEM dataset at dimensions of $30 \times 30 \mathrm{~m}$. The slope percentage dataset was processed using ArcMap software and divided into different categories according to (Mazahreh et al., 2018) for representing levels of slope suitability for rainfed agricultural and irrigated crops (Farhan and Al-Bakri.,2019). Approximately $70 \%$ of the land in the Central agriculture region has below $30 \%$ slope, $0-30 \%$ slope has good conditions for cropland in this region. It was determined that $60 \%$ of the study area has no problem in terms of receiving sunlight. The aspect map of the study area is presented in Fig. 2. In Mongolia, a sustainable agricultural region has an elevation between $600-1500 \mathrm{~m}$. Up to $1500 \mathrm{~m}$ altitudes in Central agriculture region cover 10 percent of the total area (Fig. 2).

Thematic maps were developed for each factor. Soil texture and soil humus factor maps were extracted from the digitized soil map with a scale of 1:5000,000. The resolution of all raster factor maps was set at $30 \mathrm{~m} \times 30 \mathrm{~m}$.

We used MODIS (Moderate Resolution Imaging Spectroradiometer) products as MODIS13Q1 NDVI with a resolution of $250 \mathrm{~m}$ for ten-year (2009-2019) period to observe the dynamic range of the vegetation during the growing season, the National Aeronautics and Space Administration (NASA) Earth Observing System (http://lpdaac.usgs.gov/) data were used.
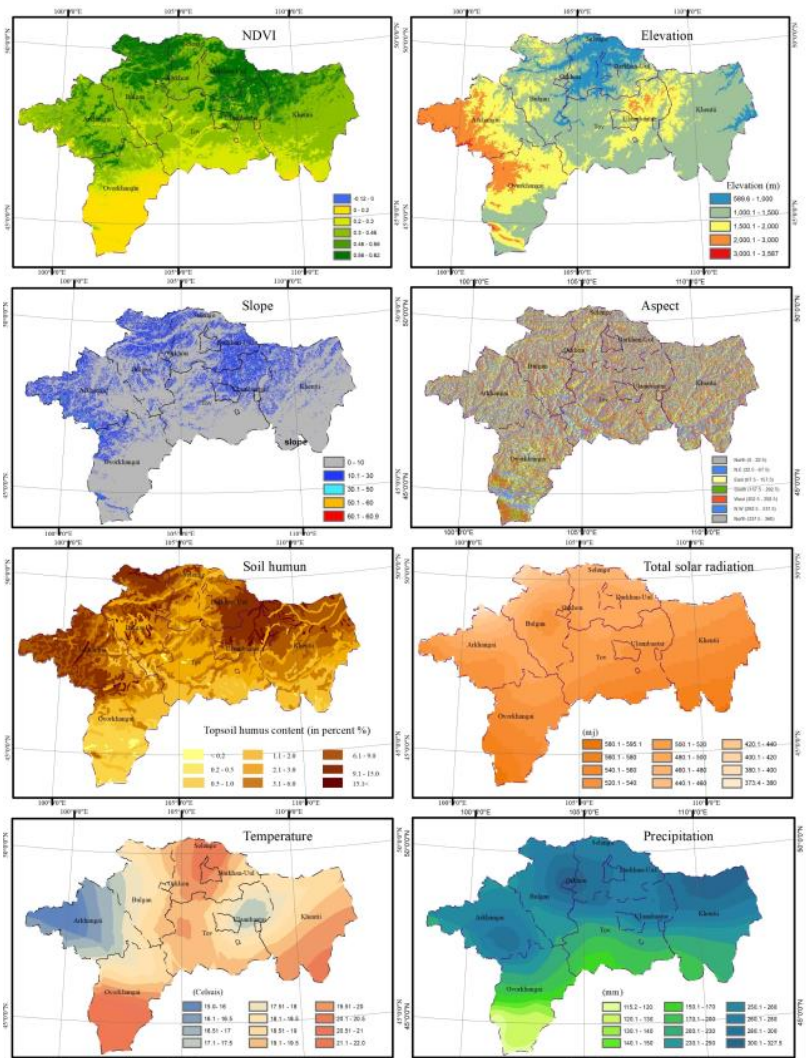

Figure 2. Agro-climate, soil and topographic factors, including precipitation, temperature, solar radiation, soil type, Soil humus, elevation, slope, aspect, and NDVI. 


\subsection{Spatial Data Analysis}

To locate land suitable for agriculture an integrated suitability assessment was conducted considering precipitation, temperature, solar radiation, soil type, Soil humus, elevation, slope percentage, aspect, and vegetation coverage. These parameters shown in Fig. 3 were used in spatial analysis that could model land suitability analysis. The weights of different evaluation factors were assigned after establishing the factor system for the suitability of cropland. The criteria structure is shown in Fig. 3. We used weighted overlay analysis for evaluation factors of cropland suitability.

The weighted overlay was used to reclassify the criteria from Table 1 to the same scale according to their influence on cropland suitability. Values from 1 to 5 (criteria standardization) were applied to each criterion, as it has been performed on a previous study as a requirement of agricultural suitability method 2015 from Administration of Land Affairs,
Geodesy and Cartography. According to the degree of suitability for cropland conservation, a value of 1 was assigned to the areas with the lowest suitability, while a value of 5 was assigned to the most suitable areas. The land suitability for the agricultural land-use areas is classified into five classes; namely; high suitable (5), suitable (4), moderately suitable (3), unsuitable (2), and highly unsuitable (1), as shown in Table 1. After reclassifying the criteria, three scenarios were generated. A scenario was produced by ranking, with the highest weight being a criterion of interest to reflect its importance for suitable cropland. The result was then represented in a map. Three weighting scenarios were considered for this study as climate, soil and topographic. The reclassification of the input maps and the suitable cropland evaluation was carried out using the reclassify and weighted overlay tool, respectively. The software used for that purpose was ArcMap 10.4@ software (ESRI, Redlands, CA, USA; https://www.esri.com/en-us/home).

\begin{tabular}{|c|c|c|c|c|c|c|c|}
\hline Criteria & Factor & Unit & $\begin{array}{l}\text { Highly Suitable } \\
\text { (5scores) }\end{array}$ & Suitable & $\begin{array}{l}\text { Moderately } \\
\text { Suitable } \\
(3 \\
\text { scores) }\end{array}$ & $\begin{array}{l}\text { Unsuitable } \\
\text { (2 scores) }\end{array}$ & $\begin{array}{l}\text { Highly } \\
\text { Unsuitable } \\
\text { (1 score) }\end{array}$ \\
\hline \multirow{3}{*}{ Topography } & Elevation & Meter & $<1000$ & $\begin{array}{c}1000- \\
1500\end{array}$ & $\begin{array}{c}1500- \\
2000\end{array}$ & $2000-3500$ & $>3500$ \\
\hline & Slope & Degree & $0-10$ & $10--30$ & $30-50$ & $50-60$ & $>60$ \\
\hline & Aspect & Degree & S (157.5-202.5) & $\begin{array}{l}\text { W, SW } \\
(202.5- \\
292.5)\end{array}$ & $\begin{array}{l}\text { E, SE } \\
(67.5- \\
157.5)\end{array}$ & $\begin{array}{c}\text { NE, NW } \\
(22.5-67.5) \\
(292.5-337.5)\end{array}$ & $\begin{array}{c}\mathrm{N}(0-22.5) \\
\mathrm{N}(337.5-360)\end{array}$ \\
\hline \multirow{3}{*}{ Soil } & Soil texture & Type & $\begin{array}{l}\text { Light clay ( } 21 \text { - } \\
\text { 30), Sandy (10 - } \\
\text { 20) }\end{array}$ & $\begin{array}{l}\text { Mid- } \\
\text { siltstone } \\
(31-45)\end{array}$ & Sand $(<10)$ & $\begin{array}{l}\text { Heavy clay }(45 \\
-60)\end{array}$ & Clay $(>60)$ \\
\hline & Soil humus & $(\%)$ & $(5-9)$ & $(1-5)$ & $(0.5-1)$ & $(0-0.5)$ & $(9-20)$ \\
\hline & NDVI & Value & $0.3-0.46$ & $0.2-0.3$ & $0.1-0.2$ & $0.46-0.56$ & $\begin{array}{c}(-1-0.1)(0.56 \\
0.9)\end{array}$ \\
\hline \multirow{3}{*}{$\begin{array}{l}\text { Agro- } \\
\text { Climate }\end{array}$} & $\begin{array}{l}\text { Sum precipitation of } \\
\text { growing season }\end{array}$ & $\mathrm{mm}$ & $250-350$ & $\begin{array}{c}150.1- \\
250\end{array}$ & $100.1-150$ & $50.1-100$ & $<50,>350$ \\
\hline & $\begin{array}{l}\text { Average temperature } \\
\text { of growing season }\end{array}$ & $\left({ }^{\circ} \mathrm{C}\right)$ & $19-23$ & $17-19$ & $15-17$ & $13-15$ & $<13,>23$ \\
\hline & $\begin{array}{l}\text { Total solar radiation } \\
\text { of growing season }\end{array}$ & (m) & $500-600$ & $400-500$ & $300-200$ & $100-200$ & $<100$ \\
\hline
\end{tabular}

Table 1. Reclassification of the criteria influencing cropland suitability.

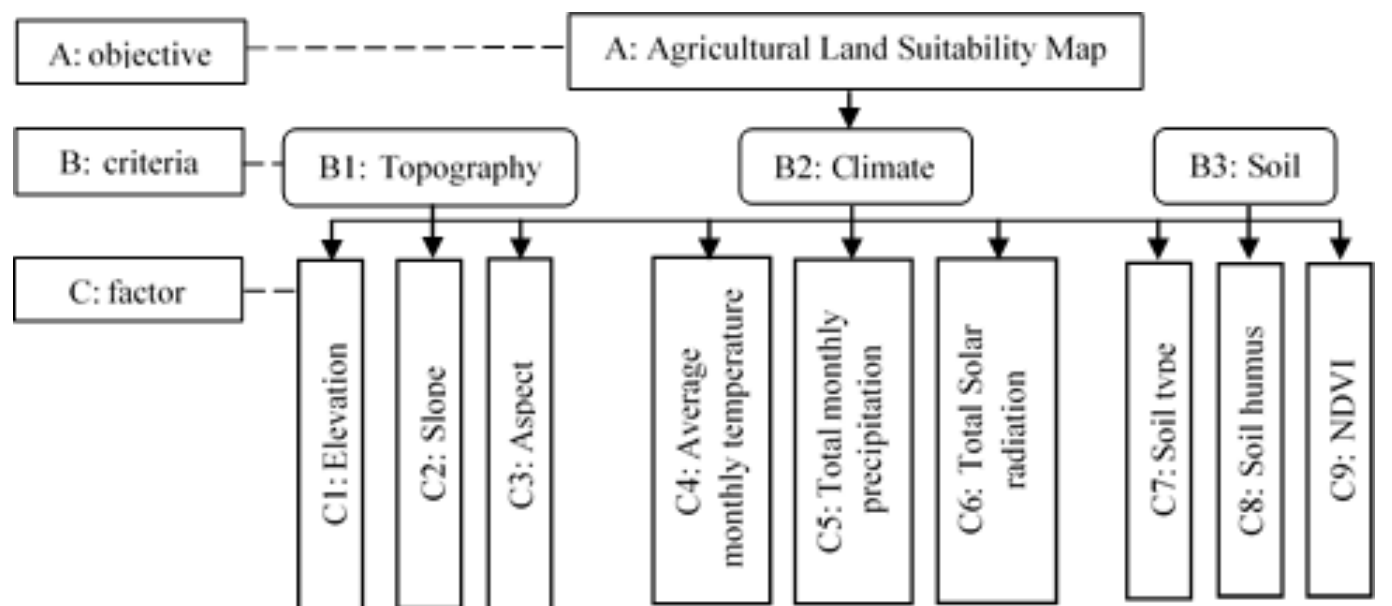

Figure 3. Criteria structure of cropland suitability evaluation factors of central Mongolia. 


\section{RESULT AND DISCUSSION}

\subsection{Cropland suitability evaluation}

According to the land-use policy in Mongolia, many land types, including forest and water body are completely unsuitable for cultivation. Therefore, these regions were classified on the evaluation map as unsuitable. Criteria of agro-climate, soil and topographic have highly suitable regions were identified as sites that are highly advantageous for the growth of crops. These study site covered total an area of 37223900.81 ha, highly suitable regions has been classified area of 20905685.46 ha on
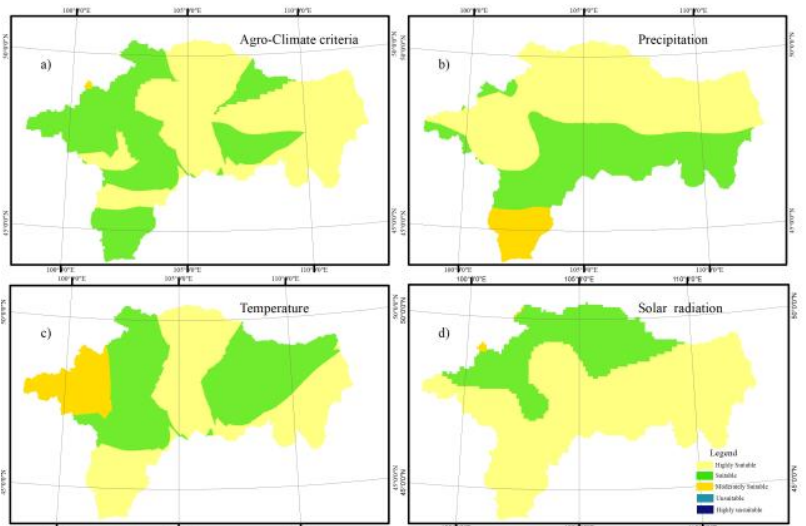

Figure 4. Generated criteria of a) agro-climate with related factors including b) precipitation, c) temperature, and d) solar radiation.
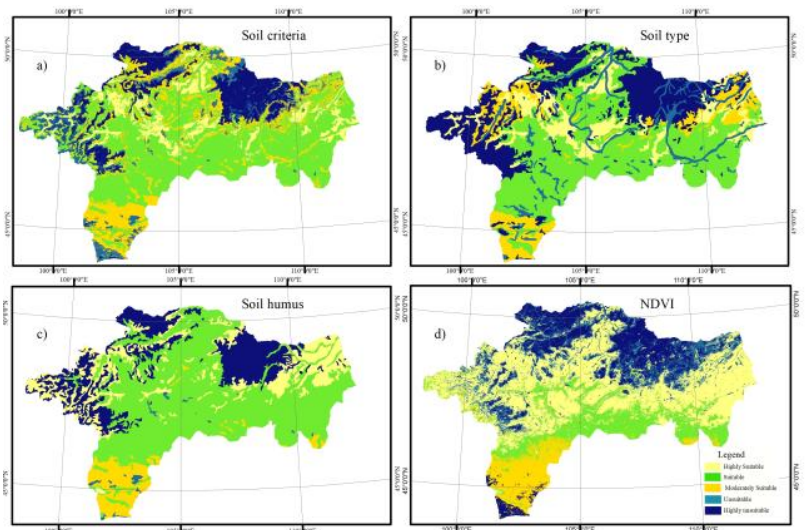

Figure 5. a) Soil criteria with related factors such as b) soil type, c) soil humus and d) NDVI.
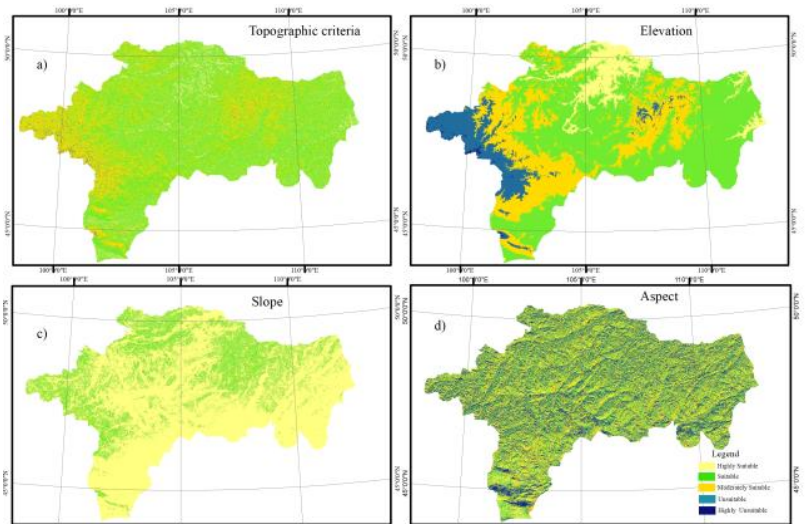

Figure 6. a) Topographic criteria with related factor as b) elevation, c) slope percentage, and d) aspect.
Agro-climate criteria which represented $56.16 \%$ of the total evaluation area (Table 2 and Fig. 4a). The suitable, and moderately suitable regions covered an area of 15841953.00 ha with $42.56 \%$, and 476262.35 ha with $1.28 \%$, respectively. The highly suitable were mainly located in the central and eastern regions of the study area. Most of suitable regions were scattered in the western region of the study area (Table 2 and Fig. 4a).

The surface areas of the land suitability categories are shown in Table 2. An area of 3446226.00 ha with $9.26 \%$ in the study area was eliminated as highly suitable regions for soil criteria (Table 2 and Fig. 5a).

Fig. 5 shown that a suitable zone was the one covering most of the surface for the three criteria with an area of 17465772.96 ha $(46.92 \%)$. The moderate suitability zone has an area of 7479196.10 ha (20.09\%) and the unsuitable and highly unsuitable zones showed a surface of 3464146.08 ha $(9.31 \%)$ and 5368559.67 ha $(14.42 \%)$, respectively. The central region of the study area was a highly suitable region. Most regions were highly advantageous for suitable of crops with soil criteria. The topographic criteria mapped in Fig. 6 and Table 2, the regions deemed highly suitable, suitable, moderately suitable, unsuitable and highly unsuitable were covered an area of 3275881.20 ha, 23745464.01 ha, 9917644.58 ha, 284904.27 ha and $6.75 \mathrm{ha}$, and accounted for $8.80 \%, 63.79 \%, 26.64 \%, 0.77 \%$ and $0.00002 \%$ of the total evaluation area, respectively.

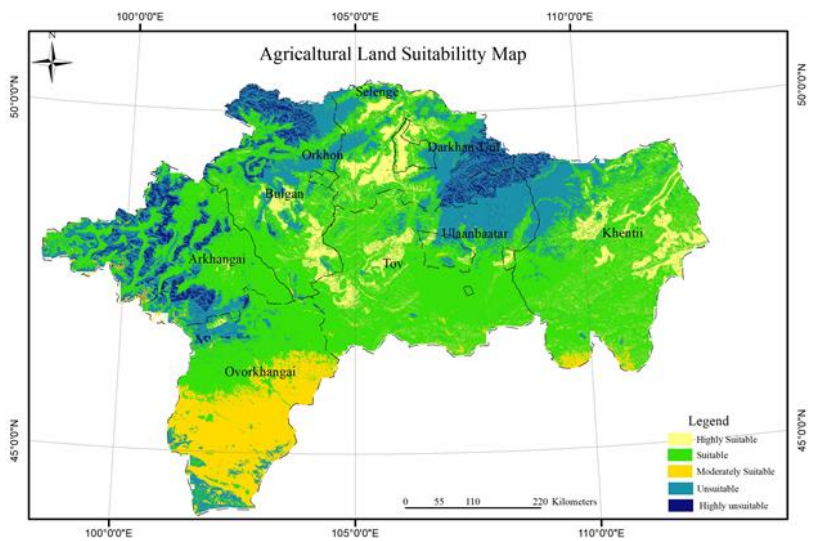

Figure 7. Obtained spatial distribution of suitable cropland in the central agricultural region of Mongolia.

According to the agricultural land use suitability map generated, it was determined that, while $3.92 \%$ (1457970.03 ha) of the study area is permanently highly unsuitable for agricultural production, $23.72 \%$ ( $8828120.07 \mathrm{ha}$ ) is currently unsuitable, $11.11 \%(4136371.55 \mathrm{ha})$ is moderately suitable, $51.95 \%$ (19338131.16 ha) is marginally suitable, and $9.30 \%$ (3463308.00 ha) is highly suitable (Table 2 and Fig. 7).

Soil and topographic criteria along with the shallow soil type of the study area were effective factors, resulting in a low rate of highly suitable agricultural land in this study. Similarly, in a study conducted to evaluate agricultural land suitability for Mongolia, parallel results were obtained, as a rate of $10.1 \%$ for highly suitable agricultural land was determined (Munkhdulam et al., 2016).

Forests and pastureland cover most areas of the study site (Fig. 7). While $51.95 \%(19338131.16 \mathrm{ha})$ of the land that is marginally suitable for agricultural use coincides with pastureland, $23.72 \%$ (8828120.07 ha) of unsuitable land and $3.92 \%$ (1457970.03 ha) of highly unsuitable land coincide with forest. Because agricultural activities cannot be carried out in 
forest and near water protection zone, pursuant to legal regulations in Mongolia.

\begin{tabular}{|c|c|c|c|c|c|c|c|c|}
\hline \multirow{2}{*}{ Sustainability } & \multicolumn{2}{|c|}{ Agro-Climate Criteria } & \multicolumn{2}{|c|}{ Topography Criteria } & \multicolumn{2}{|c|}{ Soil Type Criteria } & \multicolumn{2}{|c|}{ Suitable Cropland } \\
\hline & Area (ha) & $(\%)$ & Area (ha) & $(\%)$ & Area (ha) & $(\%)$ & Area (ha) & $(\%)$ \\
\hline $\begin{array}{l}\text { Highly Suitable } \\
\text { (5scores) }\end{array}$ & 20905685.46 & 56.16 & 3275881.20 & 8.80 & 3446226.00 & 9.26 & 3463308.00 & 9.30 \\
\hline Suitable (4 scores) & 15841953.00 & 42.56 & 23745464.01 & 63.79 & 17465772.96 & 46.92 & 19338131.16 & 51.95 \\
\hline $\begin{array}{l}\text { Modernity Suitable } \\
\text { (3 scores) }\end{array}$ & 476262.35 & 1.28 & 9917644.58 & 26.64 & 7479196.10 & 20.09 & 4136371.55 & 11.11 \\
\hline $\begin{array}{l}\text { Unsuitable ( } 2 \\
\text { scores) }\end{array}$ & - & - & 284904.27 & 0.77 & 3464146.08 & 9.31 & 8828120.07 & 23.72 \\
\hline $\begin{array}{l}\text { Highly Unsuitable } \\
\text { (1 score) }\end{array}$ & - & - & 6.75 & 0.00002 & 5368559.67 & 14.42 & 1457970.03 & 3.92 \\
\hline Total & 37223900.81 & 100 & 37223900.81 & 100 & 37223900.81 & 100 & 37223900.81 & 100 \\
\hline
\end{tabular}

Table 2. Surface area occupied by five cropland suitability classes of central agriculture region of Mongolia in three different criteria.

\subsection{Validation of evaluation results}

To verify the evaluation results, this study adopted cadastre data of the current cropland area obtained through the Administration of Land Affairs, Geodesy and Cartography to make a qualitative assessment for the evaluation map. The cadastre data of representative currently cropland were selected as the validation data located in the central agricultural region of Mongolia. A total of 8011 validation polygons with covering area of 775690.11 ha and their spatial distribution are shown in Fig. 8. Overly of these polygons showed that $37.78 \%$ (293089.14 ha) and 59.87\% (464413.77 ha) of these polygons were located in the highly suitable and suitable regions, with only $2.33 \%$ (18052.74 ha) and $0.02 \%$ (134.46 ha) of these polygons in the unsuitable and highly unsuitable regions, respectively. These validation polygons located in the unsuitable regions were mainly distributed in areas with high altitudes and steep slope.

\begin{tabular}{lcc}
\hline \multirow{2}{*}{ Sustainability } & \multicolumn{2}{c}{ Validation results } \\
\cline { 2 - 3 } & Area (ha) & $(\%)$ \\
\hline \hline Highly Suitable (5scores) & 293089.14 & 37.78 \\
Suitable (4 scores) & 464413.77 & 59.87 \\
Modernity Suitable (3 scores) & - & - \\
Unsuitable (2 scores) & 18052.74 & 2.33 \\
& & \\
Highly Unsuitable (1 score) & 134.46 & 0.02 \\
\hline Total & 775690.11 & 100 \\
\hline
\end{tabular}

Table 8. Validation results of evaluated cropland suitability based on cadastre data of the current cropland area.

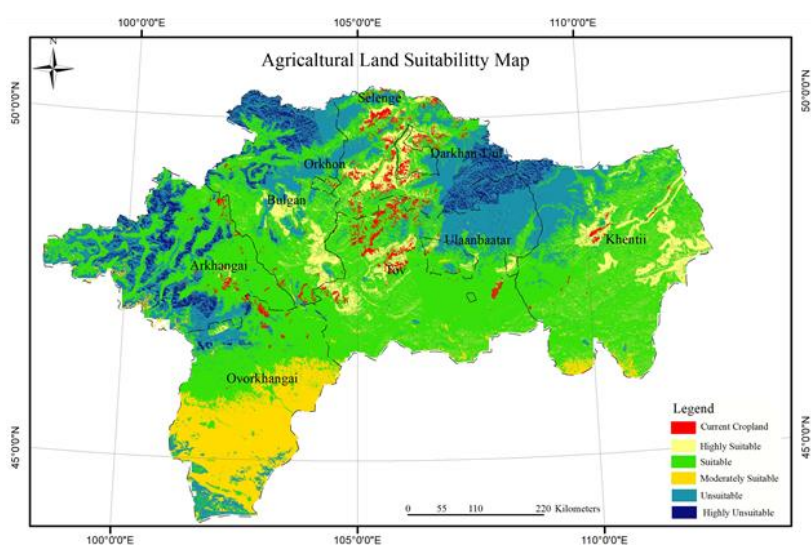

Figure 8. Spatial distribution of validation data polygons of current croplands overlapped on suitable cropland evaluation results in the central agricultural region of Mongolia.

\section{CONCLUSION}

The aim of this study was to determine the present croplands in the central agricultural region of Mongolia that is to find alternative areas suitable for agriculture using GIS and weighted overlay methods. The study was conducted using three criteria reflecting the agro-climate condition, topographical properties, and soil structure of the area. At the end of the assessment, it was estimated that part of merely $9.3 \%$ of the study area is highly suitable for agricultural production. Moreover, land suitability evaluation can function as a vital planning tool to rationally assess sustainable agricultural practices for a region and enable the prevention of a trial and error process in agricultural land use planning. Therefore, land suitability evaluation should be a mandatory step before implementing any specific land use, especially in the agricultural sector.

\section{ACKNOWLEDGMENTS}

The authors thank the Mongolian Foundation for Science and Technology for their financial support. This publication was supported financially by the project "assessment of agricultural land capacity and development a rationale for its further use'. I am grateful to my mentor Dr. Bayartungalag Batsaikhan for his helpful comments on the manuscript. We also thank the anonymous reviewers for their valuable comments, which 
greatly improved our paper. I am also grateful to ISPRS travel grant and publication fee from the ISPRS Foundation.

\section{REFERENCES}

Administration of Land Affairs, Geodesy and Cartography, http// egazar.mn

Dong, J., Liu, J., Yan, H., Tao, F. and Kuang, W., 2011. Spatiotemporal pattern and rationality of land reclamation and crop land abandonment in mid-eastern Inner Mongolia of China in 1990-2005. Environmental Monitoring and Assessment, 179(14), $137-153$.

Erdenee, B. and Tateishi, R., Development of the cropland mapping in the Selenge aimag of Mongolia using Remote sensing/GIS.

Ecosystems of Mongolia Atlas, 2019.

Farhan, I.A. and Al-Bakri, J., 2019. Detection of a Real Time Remote Sensing Indices and Soil Moisture for Drought Monitoring and Assessment in Jordan. Open Journal of Geology, 9(13), 1048-1068.

Jaehne, G., 1990. Socialist agriculture outside Europe: new ways in Mongolian agriculture. Socialist agriculture outside Europe: new ways in Mongolian agriculture, 67-89.

Mazahreh, S., Bsoul, M., Ziadat, F. and Abu Hamoor, D., 2018. Participatory land suitability analysis to identify the optimum land use for a Mountainous Watershed in Jordan. Journal of Engineering Research and Application, 8(7), pp.41-55.

Otgonbayar, M., Atzberger, C., Chambers, J., Amarsaikhan, D., Böck, S. and Tsogtbayar, J., 2017. Land suitability evaluation for agricultural cropland in Mongolia using the spatial MCDM method and AHP based GIS. Journal of Geoscience and Environment Protection, 5(9), 238-263.

Priess, J.A., Schweitzer, C., Batkhishig, O., Koschitzki, T. and Wurbs, D., 2015. Impacts of agricultural land-use dynamics on erosion risks and options for land and water management in Northern Mongolia. Environmental earth sciences, 73(2), 697708 .

Tuvdendorj, B., Wu, B., Zeng, H., Batdelger, G. and Nanzad, L., 2019. Determination of Appropriate Remote Sensing Indices for Spring Wheat Yield Estimation in Mongolia. Remote Sensing, 11(21), 2568. 